\title{
Glucose Disposal during Insulinopenia in
}

\section{Somatostatin-Treated Dogs}

\author{
THE ROLES OF GLUCOSE AND GLUCAGON
}

\author{
Gerald I. Shulman, John E. LiljenQuist, Phillip E. Williams, William W. LaCy, \\ and Alan D. Cherrington, Departments of Medicine and Physiology, Vanderbilt \\ University School of Medicine, Nashville, Tennessee 37232
}

\begin{abstract}
A B S T R A C T The first aim of this study was to determine whether the plasma glucose level can regulate hepatic glucose balance in vivo independent of its effects on insulin and glucagon secretion. To accomplish this, glucose was infused into conscious dogs whose basal insulin and glucagon secretion had been replaced by exogenous intraportal insulin and glucagon infusion after somatostatin inhibition of endogenous pancreatic hormone release. The acute induction of hyperglycemia (mean increment of $121 \mathrm{mg} / \mathrm{dl}$ ) in the presence of basal levels of insulin $(7 \pm 1 \mu \mathrm{U} / \mathrm{ml})$ and glucagon $(76 \pm 3 \mathrm{pg} / \mathrm{ml})$ resulted in a $56 \%$ decrease in net hepatic glucose production but did not cause net hepatic glucose uptake.

The second aim of the study was to determine whether a decrease in the plasma glucagon level would modify the effect of glucose on the liver. The above protocol was repeated with the exception that glucagon was withdrawn (83\% decrease in plasma glucagon) coincident with the induction of hyperglycemia. Under this circumstance, with the insulin level basal $(7 \pm 1$ $\mu \mathrm{U} / \mathrm{ml})$ and the glucagon levels reduced $(16 \pm 2 \mathrm{pg} / \mathrm{ml})$, hyperglycemia (mean increment of $130 \mathrm{mg} / \mathrm{dl}$ ) pro-
\end{abstract}

Mr. Schulman is an M.D., Ph.D. Candidate at Wayne State Medical School, Detroit, Mich. Dr. Liljenquist is an Investigator of the Howard Hughes Medical Institute. Dr. Cherrington is a recipient of the Solomon A. Berson Research and Career Development Award of the American Diabetes Association.

Received for publication 10 April 1978 and in revised form 5 June 1978. moted marked net hepatic glucose uptake $(1.5 \pm 0.2 \mathrm{mg} /$ $\mathrm{kg}$ per $\mathrm{min}$ ) and glycogen deposition. In conclusion, $(a)$ physiological increments in the plasma glucose concentration, independent of their effects on insulin and glucagon secretion, can significantly reduce net hepatic glucose production in vivo but at levels as high as $230 \mathrm{mg} / \mathrm{dl}$ cannot induce net hepatic glucose storage and $(b)$ in the presence of basal insulin the ability of hyperglycemia to stimulate net hepatic glucose storage is influenced by the plasma glucagon concentration.

\section{INTRODUCTION}

The role of glucose per se in regulating glucose production and storage by the liver has long been controversial. Early studies of Soskin et al. (1) in the dog and more recent experiments of Glinsmann et al. (2) in perfused rat liver and Bucolo et al. (3) in cross-perfused puppy livers have suggested that glucose plays the predominant role in suppressing hepatic glucose production and inducing hepatic glucose storage. Studies in vitro by Hers (4) have demonstrated that glucose, independent of insulin, can be a potent inhibitor of hepatic phosphorylase $a$ and a potent stimulator of hepatic glycogen synthase. Similar observations have been made by Buschiazzo et al. (5) and Sparks et al. (6). In addition, Ruderman and Herrera (7) have shown that glucose can inhibit gluconeogenesis in perfused livers from fasted rats.

Confirmation of these findings in vivo has not been forthcoming. Ishiwata et al. (8) raised plasma glucose 
levels in pancreatectomized dogs maintained on constant basal insulin infusions and did not observe a significant suppression of glucose production. Similarly, Wahren et al. (9) showed that human diabetics from whom insulin was withdrawn could not decrease splanchnic glucose production in response to glucose infusion. One difference between the in vitro and in vivo studies mentioned above was the absolute or relative lack of glucagon in the former $(2-7)$ and the presence of normal or increased amounts of the hormone in the latter $(8,9)$. The present experiments were undertaken to clarify the effect of glucose per se on hepatic glucose production in vivo and to determine whether the presence or absence of glucagon can modulate the effect of glucose.

\section{METHODS}

Experiments were carried out on 14 mongrel dogs (13-24 kg) of either sex. Silastic catheters were implanted under general anesthesia 17 days before study in the femoral artery and the portal, hepatic, and splenic veins as previously described (10). On the day of study, $3.8-\mathrm{cm}$ plastic catheters (17 gauge) were inserted percutaneously into a cephalic and a saphenous vein. The arterial, portal, and hepatic venous catheters were used for blood sampling, the splenic catheter was used for insulin and glucagon infusion, the cephalic catheter was used for cyclic somatostatin and cardiogreen infusion, and the saphenous catheter was used for glucose or saline infusion. The dogs were fasted $36 \mathrm{~h}$ before the experiment and were studied while standing quietly in a Pavlov harness. Multiple open liver biopsies were obtained in each dog immediately after the end of the experiment for assessment of hepatic glycogen content (11).

Each experiment consisted of a 90 -min period of hormone titration, a $30-\mathrm{min}$ control period, and a $120-\mathrm{min}$ test period. At zero time an infusion of somatostatin $(0.8 \mu \mathrm{g} / \mathrm{kg}$ per $\mathrm{min})$ was started to inhibit endogenous insulin and glucagon secretion (12). Intraportal replacement infusions of insulin (300 $\mu \mathrm{U} / \mathrm{kg}$ per $\mathrm{min}$ ) and glucagon $(1.0 \mathrm{ng} / \mathrm{kg}$ per $\mathrm{min}$ ) were started simultaneously with somatotropin release-inhibiting factor infusion. The plasma glucose level was then monitored every $5 \mathrm{~min}$ and the rate of insulin infusion was adjusted to main- tain normoglycemia. The glucagon infusion rate was never altered. The maximum change required in the insulin infusion rate was $50 \mu \mathrm{U} / \mathrm{kg}$ per min and the final mean rate of insulin infusion was $295 \pm 18 \mu \mathrm{U} / \mathrm{kg}$ per min. The last alteration in the insulin infusion rate was made at least $30 \mathrm{~min}$ before the start of the control period. Thus, during the control period of all studies glucagon and insulin were infused at a constant basal rate. Only those studies in which the plasma insulin and glucagon levels achieved during the hormone replacement period were within $20 \%$ of their preinfusion values were included.

At time $120 \mathrm{~min}$ three separate protocols were initiated. In one group of dogs $(n=4)$, the basal intraportal infusions of insulin and glucagon were continued and a peripheral saline infusion was added. In a second set of dogs $(n=5)$, the basal infusion of insulin and glucagon was continued, but acute hyperglycemia was induced and maintained by intravenous glucose infusion in a manner described previously (13). In a third set of dogs $(n=5)$, acute hyperglycemia was induced as in the previous protocol; however, coincidently the intraportal glucagon infusion was terminated and the insulin infusion alone was continued. The amount of glucose infused in the two hyperglycemic protocols was not fixed; rather, it varied according to the amount of glucose required to maintain comparable levels of hyperglycemia.

The collection and immediate processing of blood samples has been described elsewhere (14), as has the method of calculation of net hepatic glucose production (14) and the methods of immunoassay used for determination of plasma insulin and glucagon $(15,16)$.

\section{RESULTS}

The mean plasma insulin, glucagon, and glucose concentrations were similar during the control periods of all three protocols (Table I, Fig. 1). Saline infusion was without effect on any of the above parameters (Table I, Fig. 1). Infusion of glucose produced increments in the plasma glucose level of 121 and $130 \mathrm{mg} / \mathrm{dl}$, respectively, in the two protocols in which hyperglycemia was induced (Fig. 1). The plasma glucose level was raised rapidly with a priming dose of glucose and was maintained thereafter by infusion at average rates of $3.34 \pm 0.1$ and $5.21 \pm 0.2 \mathrm{mg} / \mathrm{kg}$ per $\mathrm{min}$ in the glucagon-

TABLE I

Plasma Insulin and Glucagon Concentrations Achieved during Infusions of Somatostatin Plus Intraportal Insulin $(\simeq 300 \mu \mathrm{U} / \mathrm{kg}$ per min) and Glucagon (1 $\mathrm{ng} / \mathrm{kg} \mathrm{per} \mathrm{min)}$

\begin{tabular}{|c|c|c|c|c|c|c|c|c|c|c|c|c|c|}
\hline & & \multicolumn{4}{|c|}{ Control period, min } & \multicolumn{8}{|c|}{ Test period, $\min$} \\
\hline & & 90 & 100 & 110 & $120^{*}$ & 135 & 150 & 165 & 180 & 195 & 210 & 225 & 240 \\
\hline $\begin{array}{l}\text { Saline + basal insulin } \\
+ \text { basal glucagon }\end{array}$ & $\begin{array}{l}\text { Insulin, } \mu U / m l \\
\text { Glucagon, } p g / m l\end{array}$ & $\begin{array}{r}8 \pm 1 \\
78 \pm 4\end{array}$ & $\begin{array}{r}7 \pm 1 \\
77 \pm 6\end{array}$ & $\begin{array}{r}8 \pm 1 \\
70 \pm 7\end{array}$ & $\begin{array}{r}8 \pm 1 \\
76 \pm 7\end{array}$ & $7 \pm 1$ & $\begin{array}{c}8 \pm 1 \\
73 \pm 10\end{array}$ & $8 \pm 1$ & $\begin{array}{r}8 \pm 1 \\
71 \pm 7\end{array}$ & $9 \pm 1$ & $\begin{array}{r}8 \pm 1 \\
73 \pm 7\end{array}$ & $9 \pm 1$ & $\begin{array}{r}7 \pm 1 \\
72 \pm 7\end{array}$ \\
\hline $\begin{array}{l}\text { Hyperglycemia } \\
\text { + basal insulin } \\
\text { + basal glucagon }\end{array}$ & $\begin{array}{l}\text { Insulin, } \mu U / m l \\
\text { Glucagon, } p g / m l\end{array}$ & $\begin{array}{c}9 \pm 1 \\
71 \pm 12\end{array}$ & $\begin{array}{c}9 \pm 1 \\
73 \pm 18\end{array}$ & $\begin{array}{r}9 \pm 1 \\
68 \pm 8\end{array}$ & $\begin{array}{r}9 \pm 2 \\
64 \pm 9\end{array}$ & $9 \pm 1$ & $\begin{array}{c}9 \pm 2 \\
66 \pm 10\end{array}$ & $8 \pm 1$ & $\begin{array}{r}9 \pm 1 \\
55 \pm 8\end{array}$ & $10 \pm 1$ & $\begin{array}{c}7 \pm 1 \\
67 \pm 10\end{array}$ & $8 \pm 2$ & $\begin{array}{r}8 \pm 3 \\
62 \pm 9\end{array}$ \\
\hline $\begin{array}{l}\text { Hyperglycemia } \\
\text { + basal insulin } \\
\text { (glucagon deficient) }\end{array}$ & $\begin{array}{l}\text { Insulin, } \mu U / m l \\
\text { Glucagon, } p g / m l\end{array}$ & $\begin{array}{r}8 \pm 1 \\
70 \pm 4\end{array}$ & $\begin{array}{r}7 \pm 1 \\
73 \pm 9\end{array}$ & $\begin{array}{r}8 \pm 1 \\
76 \pm 8\end{array}$ & $\begin{array}{r}7 \pm 1 \\
84 \pm 4\end{array}$ & $7 \pm 1$ & $\begin{array}{r}7 \pm 1 \\
18 \pm 3\end{array}$ & $7 \pm 1$ & $\begin{array}{r}6 \pm 1 \\
19 \pm 4\end{array}$ & $6 \pm 1$ & $\begin{array}{r}6 \pm 1 \\
13 \pm 3\end{array}$ & $7 \pm 1$ & $\begin{array}{r}7 \pm 1 \\
13 \pm 3\end{array}$ \\
\hline
\end{tabular}

* At $120 \mathrm{~min}$, an infusion of saline was begun in the first protocol. In the other two protocols, acute hyperglycemia was induced at 120 min by glucose infusion.

I Intraportal glucagon infusion discontinued at $120 \mathrm{~min}$ in this protocol. 


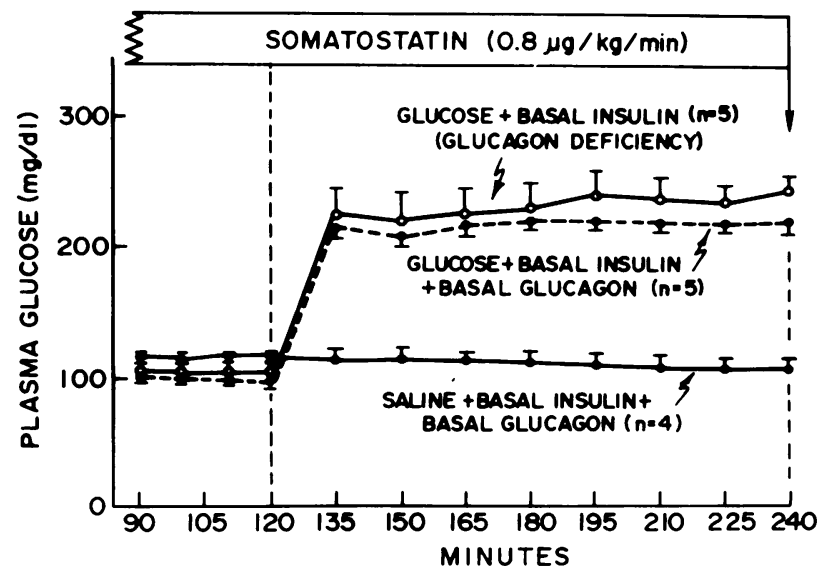

FIGURE 1 Effects of plasma glucose concentration of $(a)$ infusions of saline, somatostatin, and basal amounts of insulin and glucagon; $(b)$ infusions of glucose, somatostatin, and basal amounts of insulin and glucagon; and $(c)$ infusions of glucose, somatostatin, and basal amounts of insulin only.

replaced and glucagon-deficient groups, respectively (Table I). Total estimated hepatic blood flow did not change significantly during the study and averaged $36 \pm 5,39 \pm 5$, and $33 \pm 3 \mathrm{ml} / \mathrm{kg}$ per $\mathrm{min}$ in the salineinfused, glucagon-replaced hyperglycemic, and glucagon-deficient hyperglycemic groups, respectively.

The effects of these perturbations in plasma glucose and glucagon on net hepatic glucose balance can be seen in Fig. 2. Net hepatic glucose production remained essentially unchanged during saline infusion. Infusion of glucose in the presence of basal amounts of both insulin and glucagon, on the other hand, caused

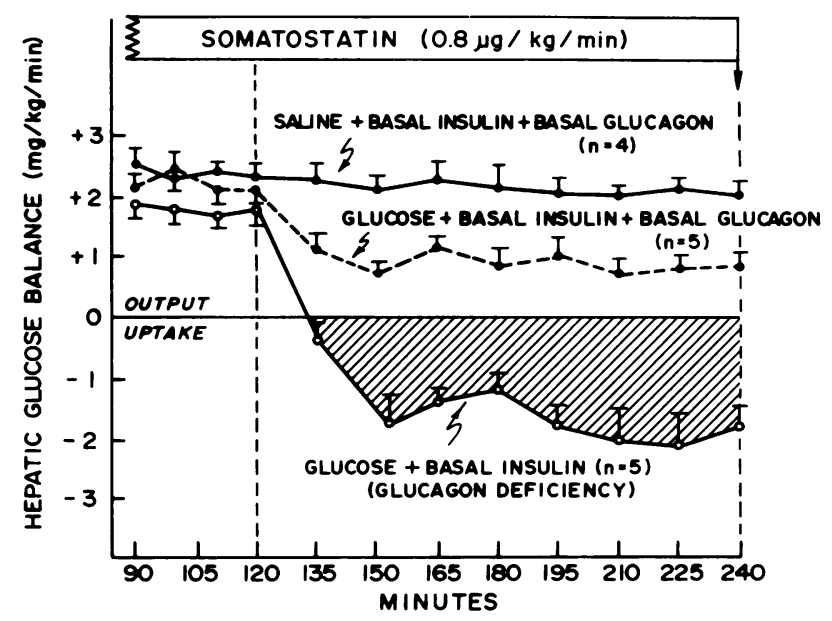

FIGURE 2 Effects on hepatic glucose balance of ( $a$ ) saline infused with somatostatin and basal amounts of insulin and glucagon; (b) hyperglycemia induced during infusions of somatostatin and basal amounts of insulin and glucagon; and (c) hyperglycemia induced during infusions of somatostatin and basal amounts of insulin only. net hepatic glucose production to decline by $56 \%$ from $2.2 \pm 0.1$ to $0.9 \pm 0.1 \mathrm{mg} / \mathrm{kg}$ per min but did not cause the liver to become a net glucose storing organ. When similar hyperglycemia was induced in the near absence of basal glucagon (basal insulin present) the liver rapidly became a glucose consuming organ, switching from a control period glucose output of $1.8 \pm 0.2 \mathrm{mg} / \mathrm{kg}$ per min to a test period uptake of $1.5 \pm 0.2 \mathrm{mg} / \mathrm{kg}$ per min.

Measurement of hepatic glycogen content at the end of each experiment (Table II) supported the hepatic glucose uptake data in that the liver glycogen levels in the animals which exhibited net glucose uptake were significantly greater $(P<0.01)$ than the hepatic glycogen levels in the other two groups.

\section{DISCUSSION}

The present study indicates that a physiological rise in plasma glucose in the absence of any change in the circulating levels of insulin and glucagon can significantly inhibit net hepatic glucose production. This finding could be explained by enhanced hepatic glucose uptake or decreased hepatic glucose production. Glucose has been shown to inhibit both glycogenolysis and gluconeogenesis in vitro and to stimulate hepatic glycogen deposition (3-7). It is thus possible that both processes were affected. The inability of Ishiwata et al. (8) and Wahren et al. (9) to demonstrate suppressive effects of glucose on hepatic glucose output in vivo may be a result of the fact that the increments in plasma glucose achieved in their studies were less than those produced in the present experiments. In addition, the diabetic subjects of Wahren et al. (9) had been withdrawn from insulin for $24 \mathrm{~h}$ and basal amounts of insulin may be necessary for glucose to suppress glucose production. In that regard, Miller has recently shown that glucose is completely ineffective in modulating the activities of glycogen synthase and phosphorylase in perfused livers of insulin-deprived diabetic rats (17) and that the sensitivity of the liver to glucose is restored by insulin treatment before perfusion.

\section{TABLE II}

Hepatic Glycogen Levels at Conclusion of Study in Dogs from Three Protocols Employed

\begin{tabular}{lc}
\hline & $\begin{array}{c}m g \text { glycogen/g } \\
\text { liver }\end{array}$ \\
$\begin{array}{l}\text { Saline + basal insulin + basal glucagon }(n=4) \\
\begin{array}{l}\text { Hyperglycemia + basal insulin + basal } \\
\text { glucagon }(n=5)\end{array}\end{array}$ & $20.8 \pm 3.3$ \\
$\begin{array}{l}\text { Hyperglycemia }+ \text { basal insulin (isolated } \\
\text { glucagon deficiency) }(n=5)\end{array}$ & $19.4 \pm 2.2$ \\
\hline
\end{tabular}

* Significantly different from other two protocols $(P<0.01)$. 
While the induction of hyperglycemia in the present study was capable of decreasing net hepatic glucose production it did not cause net glucose storage by the liver. This finding is not consistent with in vitro observations that glucose per se can activate glycogen synthase and can cause net hepatic glucose uptake and glycogen storage $(2-6)$. While many of the in vitro studies employed unphysiologically high glucose concentrations (up to $55 \mathrm{mM}$ ) some $(2,3)$ used levels within the physiologic range. One possible explanation for the difference is that glucagon, which was absent or deficient in the in vitro studies (2-7) but present in normal or elevated amounts in the in vivo experiments $(8,9)$, might influence the sensitivity of the liver to glucose. The present study was designed to test this possibility by controlling the glucose load delivered to the liver (the product of the blood glucose concentration entering the liver and hepatic blood flow) and by varying only the plasma glucagon concentration. Our findings demonstrate that the ability of the liver to handle a glucose load in the presence of a fixed basal amount of insulin was enhanced when glucagon was deficient. This observation thus supports the possibility that one of the reasons for the discrepancy between the in vitro and in vivo studies was the differing glucagon concentrations.

The present study thus suggests that under certain circumstances glucagon may play a role in determining the ability of the body to handle a glucose load. Initially, Unger and Lefebvre proposed that the decline in plasma glucagon seen during glucose ingestion was of considerable importance in reducing opposition to insulin-induced hepatic glucose uptake (18). More recently, Sherwin et al. (19) showed that oral glucose tolerance in normal man was similar in the presence of basal or elevated glucagon concentrations suggesting that glucagon played little or no role in determining the rate of glucose disposal when hyperglycemia was accompanied by hyperinsulinemia. Many insulindependent diabetics, however, cannot respond to a glucose challenge with enhanced insulin secretion and are dependent upon insulin injected several hours earlier to handle an incoming glucose load. Such diabetics, however, have basal levels of glucagon and may actually increase their glucagon levels if protein is ingested along with carbohydrate. The results of the present study suggest that during insulinopenia, when the body cannot respond to a glucose challenge with enhanced insulin secretion, the plasma glucagon level can determine the ability of the liver to dispose of a glucose load and can thereby affect the resulting blood glucose level. These results, if applicable to diabetic man with low but fixed circulating insulin levels, would suggest that suppression of glucagon secretion at times of mixed meal ingestion would reduce postprandial hyperglycemia.
Implicit in the use of somatostatin in studies such as this is the assumption that any nonpancreatic actions which it has have no effect on glucose production. This assumption is supported by the finding that simultaneous replacement of both insulin and glucagon during somatotropin release-inhibiting factor administration at a rate of $0.8 \mu \mathrm{g} / \mathrm{kg}$ per min prevented significant changes in any of the measured parameters. Such findings are also in agreement with our previous data (12), with our observation that somatostatin failed to significantly alter basal or hormone stimulated glucose output by hepatocytes (20) and with our finding that somatotropin release-inhibiting factor failed to alter basal or hormone-stimulated glucose uptake by fat or muscle (20). The lack of an effect of somatostatin on the liver in vitro is in agreement with the work of some $(21,22)$ but not all others $(23,24)$. It should be noted, however, that even when effects of somatostatin on glucose production have been observed, the concentration of the peptide required to elicit the effect was substantially greater than the levels which result from the infusion of the peptide into whole animals at rates similar to those used in the present study.

In conclusion, $(a)$ hyperglycemia of $230 \mathrm{mg} / \mathrm{dl}$ in the presence of basal amounts of insulin and glucagon is capable of exerting a significant inhibitory effect on net hepatic glucose production but cannot convert the liver to an organ of net glucose storage; and $(b)$ in the presence of basal plasma insulin, the ability of hyperglycemia to stimulate net hepatic glucose storage is influenced by the plasma glucagon concentration.

\section{ACKNOWLEDGMENTS}

The authors would like to acknowledge the excellent technical skills of Barbara Santoro and Susan Krakau, and we are most grateful for the excellent secretarial skills of Carolyn Sielbeck.

This investigation was supported by U.S. Public Health Service grant AM 18243 and Vanderbilt University DiabetesEndocrinology Center grant AM 17026.

\section{REFERENCES}

1. Soskin, S., H. E. Essex, J. F. Herrick, and F. C. Mann. 1938. The mechanism of the regulation of blood sugar by the liver. Am. J. Physiol. 124: 558-567.

2. Glinsmann, W. H., E. P. Hern, and A. Lynch. 1969. Intrinsic regulation of glucose output by rat liver. Am. J. Physiol. 216: 698-703.

3. Bucolo, R. J., R. N. Bergman, D. J. Marsh, and F. E. Yates. 1974. Dynamics of glucose autoregulation in the isolated, blood-perfused canine liver. Am.J. Physiol. 227: 209-217.

4. Hers, H. G. 1976. The control of glycogen metabolism in the liver. Annu. Rev. Biochem. 45: 167-189.

5. Buschiazzo, H., J. H. Exton, and C. R. Park. 1970. Effect of glucose on glycogen synthetase, phosphorylase, and glycogen deposition in the perfused rat liver. Proc. Natl. Acad. Sci. U. S. A. 65: 383-387.

6. Sparks, J. W., A. Lynch, and W. H. Glinsmann. 1976. Regulation of rat liver glycogen synthesis and activities 
of glycogen cycle enzymes by glucose and galactose. Metab. Clin. Exp. 25: 47-55.

7. Ruderman, N. B., and M. G. Herrera. 1968. Glucose regulation of hepatic gluconeogenesis. Am. J. Physiol. 214: 1346-1351.

8. Ishiwata, K., G. Hetenyi, Jr., and M. Vranic. 1969. Effect of D-glucose or D-ribose on the turnover of glucose in pancreatectomized dogs maintained on a matched intraportal infusion of insulin. Diabetes. 12: 820-827.

9. Wahren, J., P. Felig, E. Cerasi, and R. Luft. 1972. Splanchnic and peripheral glucose and amino acid metabolism in diabetes mellitus. J. Clin. Invest. 51: 1870-1878.

10. Keller,U., A. D. Cherrington, and J. E. Liljenquist. 1978. Ketone body turnover and net hepatic ketone production in fasted and diabetic dogs. Am. J. Physiol. In press.

11. Chan, T. M., and J. H. Exton. 1976. A rapid method for the determination of glycogen content and radioactivity in small quantities of tissue or isolated hepatocytes. Anal. Biochem. 71: 96-99.

12. Cherrington, A. D., J. L. Chiasson, J. E. Liljenquist, A. S. Jennings, U. Keller, and W. W. Lacy. 1976. The role of insulin and glucagon in the regulation of basal glucose production in the postabsorptive dog. J. Clin. Invest. 58: 1407-1418.

13. Andres, R., R. S. Swerdloff, T. Pozefsky, and D. Coleman. 1966. Manual feedback technique for control of blood glucose concentration. In Automation in Analytical Chemistry. L. J. Skeggs, Jr., editor. Mediad, Inc., New York. $486-491$.

14. Keller, U., J. L. Chiasson, J. E. Liljenquist, A. D. Cherrington, A. S. Jennings, and O. B. Crofford. 1977. The roles of insulin, glucagon and free fatty acids in the regulation of ketogenesis in dogs. Diabetes. 26: 1040-1051.

15. Aguilar-Parada, E., A. M. Eisentraut, and R. H. Unger. 1969. Pancreatic glucagon secretion in normal and diabetic subjects. Am. J. Med. Sci. 257: 415-419.
16. Wide, L., and J. Porath. 1966. Radioimmunoassay of proteins with the use of Sephadex-coupled antibodies. Biochim. Biophys. Acta. 130: 257-260.

17. Miller, T. B., Jr. 1978. Effects of diabetes on glucose regulation of enzymes involved in hepatic glycogen metabolism. Am. J. Physiol. 234: E13-E19.

18. Unger, R. H., and P. J. Lefebvre. 1972. Glucagon physiology. In Glucagon. P. J. Lefebvre and R. $\mathrm{H}$. Unger, editors. Pergamon Press, Inc., Elmsford, N. Y. 213-244.

19. Sherwin, R. S., M. Fisher, R. Hendler, and P. Felig. 1976. Hyperglucagonemia and blood glucose regulation in normal, obese, and diabetic subjects. N. Engl. J. Med. 294: 455-461.

20. Cherrington, A. D., M. D. Caldwell, M. R. Dietz, J. H. Exton, and O. B. Crofford. 1977. Effect of somatostatin on glucose uptake and production by rat tissues in vitro. Diabetes. 26: 740-748.

21. Chideckel, E., J. Palmer, D. H. Keorker, J. Ensinck, M. B. Davidson, and C. J. Goodner. 1975. Somatostatin blockade of acute and chronic stimuli of the endocrine pancreas and consequences of this blockade on glucose homeostasis. J. Clin. Invest. 55: 754-762.

22. Gerich, J. E., D. Bier, R. Haas, C. Wood, R. Byrne, and J. C. Penhos. 1975. In vitro and in vivo effects of somatostatin on glucose, alanine and ketone metabolism in the rat. Endocrinology. 96: A128. (Abstr.)

23. Oliver, J. R., and S. R. Wagle. 1975. Studies on the inhibition of insulin release, glycogenolysis and gluconeogenesis by somatostatin in rat islets of transplants and isolated hepatocytes. Biochem. Biophys. Res. Commun. 62: 722-777.

24. Sacks, H., K. Waligora, J. Matthews, and B. Pimstone. 1977. Inhibition by somatostatin of glucagon-induced glucose release from the isolated perfused rat liver. Endocrinology. 101: 1751-1759. 